\title{
Análise dos elementos estratégicos em processos de internacionalização: empresas brasileiras de real estate visando ao mercado residencial da Costa Rica
}

\author{
Analysis of the strategic elements in internationalization \\ processes: Brazilian real estate companies targeting the \\ residential market of Costa Rica
}

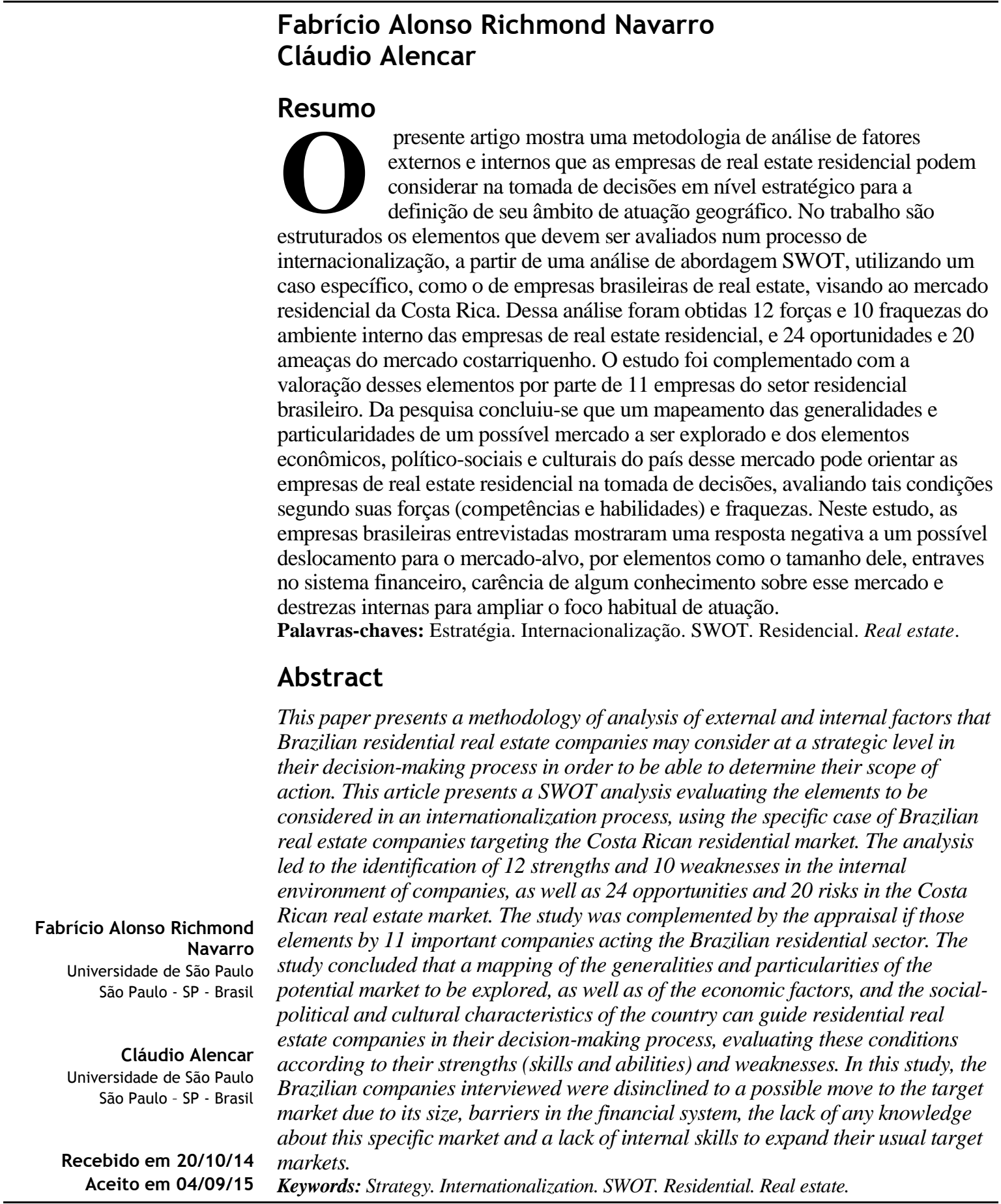

NAVARRO, F. A. R.; ALENCAR, C. Análise dos elementos estratégicos em processos de internacionalização: empresas brasileiras de real estate visando ao mercado residencial da Costa Rica. Ambiente Construído, Porto Alegre, v. 16, n. 1,p. 285-299, jan./mar. 2016.

ISSN 1678-8621 Associação Nacional de Tecnologia do Ambiente Construído.

http://dx.doi.org/10.1590/s1678-86212016000100074 


\section{Introdução}

Não existe empresa de real estate imune às ameaças de seu entorno. Em situações de saturação de mercado, declínio geral da procura, pressões da concorrência e obsolescência dos produtos, é relevante que se revisem as estratégias de produção e de mercado para uma reformulação. Ansoff (1977) denomina esses elementos de estímulos geradores, dos quais são derivadas muitas das evoluções nas estratégias das empresas. Um exemplo disso seria o desenvolvimento de novos mercados.

A literatura sobre internacionalização de empresas cita várias condições externas que podem motivar essa estratégia, como a busca de novos mercados quando seus mercados internos não são capazes de absorver sua produção, para assim evitar a dependência de um único mercado ao diversificar os pontos de atuação (KOTLER, 2000). Também, as motivações podem decorrer de ações de concorrentes e de clientes, os quais obrigam à melhoria da competitividade da empresa, com serviços globalizados e de maior qualidade (ANSOFF, 1977; PORTER, 1990; BARDHAN; KROLL, 2007).

São listadas, ainda, as situações internas como o empreendedorismo internacional, ligado a questões de gerenciamento e mentalidade global, na procura do aperfeiçoamento da empresa (NUMMELA; SAARENKETO; PUUMALAINEN, 2004).

Observam-se condições propícias para que as empresas de real estate residencial saiam de suas fronteiras habituais de atuação para uma perspectiva internacional, e que aproveitem as características intrínsecas de seu setor, nas atuais economias globalizadas.

Porém, a literatura desse fenômeno é escassa. Em sua maioria, as empresas com atividade internacional são do setor manufatureiro, que, pelo tipo de atividade que realizam, podem mudar seu envolvimento no novo mercado, no qual podem ampliar a introdução em diferentes tipos de estágios (OSLAND; TAYLOR; ZOU, 2001).

No tema da internacionalização da construção civil, a maioria das pesquisas enfoca-se nas empresas de construção pesada (VARGAS, 2008; SCHERER; GOMES; KRUGLIANSKAS, 2009; JUNG et al., 2010), mas o desempenho desses tipos de empresas difere das considerações que deveria ter uma empresa com atuação na área residencial, a qual deve estar mais consciente do contexto local (questões mercadológicas, técnicas e legais) para a formatação de seus produtos, com uma inserção quase total no novo mercado.
Em uma procura mais aprofundada da literatura específica da área de real estate, o tema da internacionalização tem dois focos de importante peso. O primeiro trata da avaliação dos principais riscos e das oportunidades de rentabilidade do ponto de vista dos investidores, quando estes diversificam seu portfólio de investimento em mercados internacionais, como mediante a compra de títulos ou ações (BARDHAN; KROLL, 2007; ROCHA LIMA; ALENCAR, 2008). Um segundo foco trata da internacionalização de serviços de corretagem de propriedades (ALON; BIAN, 2005; BARDHAN; KROLL, 2007).

Portanto, a contribuição deste trabalho é apresentar uma metodologia de análise de fatores externos e internos, os quais as empresas de real estate residencial poderiam considerar para a tomada de decisões em nível estratégico, na definição de seu âmbito de atuação geográfico. De tal forma, estuda-se um processo atípico para essas empresas, dentro da temática do planejamento estratégico.

O objetivo do presente trabalho é estruturar os elementos estratégicos que devem ser avaliados num processo de internacionalização, a partir de uma análise de abordagem Swot $^{1}$, utilizando um caso específico, como o das empresas brasileiras de real estate, visando ao mercado residencial da Costa Rica.

O artigo está estruturado com esta seção introdutória, seguida da apresentação dos fundamentos teóricos da internacionalização de empresas, utilizados para analisar o problema de empresas brasileiras, visando ao mercado da Costa Rica. A terceira seção expõe a metodologia utilizada para analisar o fenômeno citado, obtendo assim, na seção seguinte, os elementos dessa análise. Na penúltima seção são apresentados os resultados da tomada de decisões de várias empresas do setor residencial, diante desses elementos. As conclusões do trabalho são apresentadas na última seção.

\section{Avaliação de estratégias de expansão internacional}

As teorias de internacionalização dividem as empresas que globalizam suas atividades em duas: as de enfoque global, feitas para se desenvolver em ambientes internacionais; e as de estágios de internacionalização, que, por meio de processos sequenciais, conseguem levar suas atividades fora

${ }^{1}$ Swot, sigla em inglês de strengths, weakness, opportunities and threats; em português, forças, fraquezas, oportunidades e ameaças (Fofa). 
de seus mercados locais (ZAPLETALOVA, 2014). Este último modelo é o mais predominante para a explicação da internacionalização das firmas e foi desenvolvido pela Universidade de Uppsala, com base no modelo de desenvolvimento das firmas suecas manufatureiras na década de 1970 .

Espera-se que empresas de real estate residencial, no caso das aqui estudadas, se situem no grupo da internacionalização incremental. Isso sugere o direcionamento das empresas para mercados similares aos quais elas vêm operando, em "uma sequência de passos de natureza incremental", que se alimenta da aprendizagem para subir de nível no comprometimento da empresa. Dessa forma, podem-se eleger mercados mais próximos, com características similares às de seus mercados locais, por exemplo, com culturas parecidas (PRANGE; VERDIER, 2011).

Mas o que motivaria as empresas do setor residencial a procurar novos mercados? A literatura de estratégia empresarial e internacionalização das empresas expõe várias condições que poderiam incentivar as empresas a expandir seu foco de atuação nos mercados internacionais, propiciadas pelo ambiente externo ou interno da empresa.

Sendo assim, situações externas como a de mercados mais lucrativos, ou de maior tamanho que o habitual, poderiam, segundo Kotler (2000), diversificar os pontos de atuação da empresa e evitar a dependência de um único mercado. Surge então uma condição mais atrativa quando a produção da empresa não pode ser absorvida pelos atuais mercados de atuação, ou quando clientes, que representam parte importante do portfólio de investimento, mudam de geografia. Este último motivo é o que tem levado várias empresas de real estate dos Estados Unidos a sair de suas fronteiras e diversificar seus produtos no exterior (BARDHAN; KROLL, 2007).

Ansoff (1977) indica que situações adversas podem motivar o reforço das competências de produção da empresa, sendo a internacionalização um modo de atingir esse objetivo. Entre essas possíveis ameaças, destacam-se a saturação do mercado atual, o declínio geral da procura por obsolescência do produto, devido a mudanças nos costumes e hábitos da sociedade, e pressões dos concorrentes locais. Kotler (2000) cita como ameaça os concorrentes de mercados vizinhos, que poderiam entrar nos mercados habituais da empresa com produtos diferenciados.

Porter (1990), em outra perspectiva, explica que elementos mercadológicos, como a concorrência local e as características dos clientes dos mercados locais, podem criar uma vantagem competitiva para concorrer em mercados internacionais. Isso acontece devido às condições do mercado habitual, que levariam as empresas à inovação, melhoramento e procura de altos patamares de produção e de tecnologia.

Entretanto, mesmo sem alguma ameaça que obrigue a mudança de estratégia por parte da empresa, a opção de se chegar a mercados em outras latitudes pode ser produto de uma visão mais global e de um empreendedorismo empresarial (NUMMELA; SAARENKETO; PUUMALAINEN, 2004), sendo essas iniciativas ferramentas para a competitividade da empresa em qualquer mercado (ZAPLETALOVA, 2014). É possível conseguir, por meio de extensão das atividades em níveis internacionais, uma cultura adaptável e flexível, capaz de aprender e aceitar as mudanças dos mercados, ajustando-se às ocorrências nesses ambientes adversos (PRANGE; VERDIER, 2011).

Outra condição interna que motiva a internacionalização da empresa é o desejo de crescimento, como estuda Ansoff (1977), no qual primeiramente a empresa procuraria as necessidades existentes para seus produtos atuais nos diversos segmentos da sociedade de outros países, até processos mais complexos e de maior risco, criando novos produtos nesses novos mercados

Portanto, uma vez encontradas as motivações para uma expansão internacional, o movimento da empresa ocorrerá pela combinação de fatores externos e de um ambiente interno propício, utilizando todas as sinergias possíveis nessa nova área de mercado, produto das competências essenciais organizacionais (PRAHALAD; HAMEL, 1998). Preferencialmente, a escolha do mercado para a expansão deve ser baseada nos recursos da empresa (PRANGE; VERDIER, 2011) e do método de entrada no novo mercado (OSLAND; TAYLOR; ZOU, 2001), procurando sempre considerar as vantagens competitivas sobre a concorrência local.

A avaliação ambiental interna e externa (ver Figura 1) seria um dos primeiros estágios da tomada de decisões ante esse tipo de processo (ANSOFF, 1977; KOTLER; KELLER, 2006). Uma análise de tipo Swot se adequaria a esse caso, pois levantaria elementos de planejamento com base na análise interna das empresas de real estate residencial e das condições ambientais do mercado costarriquenho. 


\section{Análise Swot}

A análise Swot examina, primeiramente, os elementos internos como análise de seus recursos, pessoal, facilidades, locação, produtos, serviços, habilidades e competências; e posteriormente analisa os fatores externos ao mercado, como as forças macroambientais: economia, demografia, tecnologia, legislação, política e sociocultura; e agentes microambientais: clientes, concorrentes, distribuidores e fornecedores (KOTLER; KELLER, 2006).

Essa análise procura acoplar os ambientes internos e externos simultaneamente, para depois incrementar os efeitos sinérgicos da empresa. Desse modo, são estruturadas estratégias "agressivas" para uso dos pontos fortes como critério de busca, com o objetivo de aproveitar as oportunidades do mercado e enfrentar as ameaças. Também podem ser utilizadas estratégias "defensivas", que procuram eliminar os pontos fracos da organização e evadir as ameaças existentes (ANSOFF, 1977; DYSON, 2004).

Kotler e Keller (2006) explicam que, nos mercados, encontram-se oportunidades quando há possibilidade de oferecer produtos ou serviços cujas ofertas sejam escassas, quando produtos existentes forem apresentados de maneira diferente e/ou com qualidades superiores, ou quando algo é totalmente novo. Por outro lado, as ameaças ambientais são um desafio imposto por uma tendência ou evento desfavorável, cujas vendas ou lucros se deteriorariam na ausência de ações defensivas.

\section{Metodologia}

Para se obter o objetivo principal deste trabalho, dividiu-se o problema em três partes. A primeira consta de uma revisão bibliográfica, que tem por objetivo procurar no ambiente interno de empresas de real estate residencial as forças e fraquezas para esse tipo de estratégia. A segunda parte consta de uma análise do ambiente externo, o qual distingue as oportunidades e ameaças para empresas de real estate residencial, considerando o ambiente macroeconômico e as principais conjunturas político-legais e socioculturais da Costa Rica, além das características próprias do mercado residencial costarriquenho.

$\mathrm{Na}$ última parte utilizou-se dos elementos estratégicos distinguidos na análise para conhecer as decisões de várias empresas brasileiras de real estate residencial ante a estratégia em questão. Para isso, foi estruturado um questionário com a informação da análise Swot, aplicado em uma entrevista com um membro de cada empresa, o qual tivera peso nas decisões sobre a definição do âmbito de atuação da companhia.

\section{Escolha do mercado da Costa Rica e das empresas brasileiras}

Foram consideradas para o estudo deste caso as empresas do setor residencial brasileiro, pois, devido ao aumento no volume de obras realizadas nos últimos anos, essas empresas tiveram um crescimento em seus recursos tangíveis e intangíveis (SOUZA, 2011), adquirindo novas habilidades e competências capazes de atingir novos âmbitos de atuação dentro de sua estratégia empresarial, como o internacional, além de ser empresas economicamente robustas, que podem avistar novos horizontes de atuação para cumprir suas expectativas de crescimento.

Figura 1 - Decisões no processo de formulação de estratégias

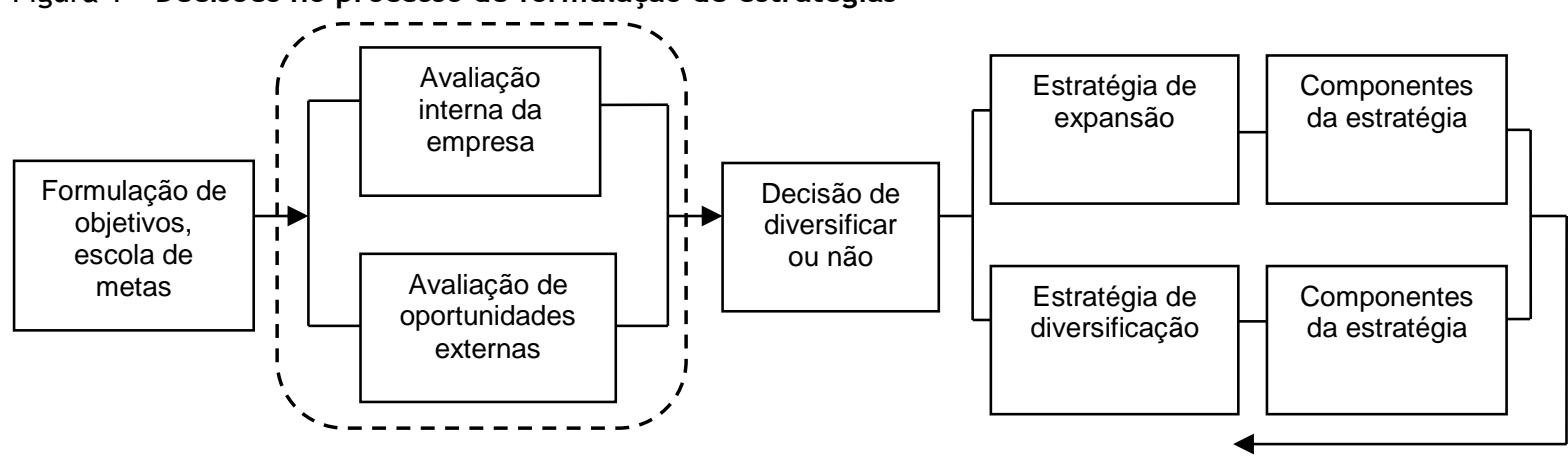

Regras de decisão para busca e avaliação

Fonte: Ansoff (1977, p. 23). 
Assim, também foi levantado como possível alvo dessas empresas o mercado costa-riquenho, devido às oportunidades distinguidas a priori, que são produto das recentes políticas de incentivo para projetos de alta densidade populacional, tais como:

(a) a "Política Nacional de Ordenamento Territorial 2012 a 2040” (PNOT), que visa promover os assentamentos humanos e as atividades econômicas e sociais para o bem-estar da população, com uso dos recursos naturais, e a conservação do meio ambiente como ferramenta de planejamento estratégico a longo prazo (MINISTÉRIO..., 2012); e

(b) o "Plano de Ordenamento Territorial da GAM 2011-2030 (POT/GAM)", que impacta uma região economicamente importante e com alta densidade populacional, como é a Grande Área Metropolitana (GAM), e tem como objetivo "[...] um crescimento urbano racional, evitando a dispersão, a baixa densidade e o uso subótimo da infraestrutura; e que se integre e respeite o meio natural existente.” (MINISTÉRIO..., 2012, p. 24).

Essas políticas fortalecem antigos programas, como o de "Regeneração e Repovoamento do São José", que teve como origem a promoção da renovação do centro da capital do país devido à deterioração, abandono e obsolescência em que se encontrava antes dessa legislação. Elas pretendem reverter também o processo de despovoamento, especialmente nos centros urbanos deprimidos, incentivando as empresas privadas, que alinham seus produtos com os objetivos do Programa. Estima-se que para o ano de 2030 serão necessárias 250.000 novas moradias somente na área metropolitana do país (MINISTÉRIO..., 2012a).

Por último, parte da escolha do mercado costariquenho e das empresas brasileiras se deve ao motivo de os autores terem experiência no estudo desses elementos, o que facilita a compreensão do problema.

\section{Avaliação do ambiente interno}

$\mathrm{Na}$ compreensão de que a estratégia de internacionalização tem dois níveis de complexidade, um deles referente à ampliação do foco habitual de atuação das atividades e outro referente ao desempenho competitivo no novo mercado, o desenvolvimento de uma análise interna terá essa divisão de dimensões. Em outras palavras, primeiramente mostrará os elementos interiores à empresa, envolvidos nos processos de internacionalização, e depois mostrará os elementos próprios do desempenho de seus negócios.
Para analisar o primeiro nível, utilizou-se a literatura sobre internacionalização de empresas, resgatando as forças e fraquezas que podem ser encontradas nas empresas de real estate residencial (LORD; RANFT, 2000; BARDHAN; KROLL, 2007; VARGAS, 2008, JAVERNICK-WILL, 2009; PRANGE; $\quad$ VERDIER, 2011; ZAPLETALOVA, 2014).

No segundo nível valeu-se da informação própria de real estate, com o reconhecimento dos elementos estratégicos e das competências propostas pela literatura como aspectos intrínsecos a essas empresas. Baseou-se no estudo de Linjie (2011), por este possuir uma abordagem similar à teoria de análise Swot na integração dos recursos internos e externos e por definir competências principais para as empresas de real estate. Além disso, o tema foi complementado com o incremento das áreas de conhecimento necessárias para esse tipo de empresa com o trabalho de Gibler, Black e Moon (2002) e Manning e Epley (2006).

Os resultados dessa análise são apresentados na seção "Elementos de análise Swot".

\section{Avaliação do ambiente externo}

Para a primeira parte desta análise foram consideradas as principais conjunturas econômicas, político-legais e socioculturais da Costa Rica, que influem em seu mercado residencial. Todas essas conjunturas representam para as empresas estrangeiras uma "fronteira" entre seu país e o novo país (JAVERNICK-WILL, 2009).

Em relação à conjuntura econômica foi analisado o ambiente macroeconômico do país por meio de indicadores, tais como Produto Interno Bruto (PIB), Investimento Direto Estrangeiro (IDE), Índice Mensal de Atividade Econômica (IMAE), Índice de Preços ao Consumidor (IPC), regime de câmbio da moeda local relativo ao dólar, emprego e pobreza.

$\mathrm{Na}$ parte político-legal foram analisadas políticas e legislações que impactam o setor residencial, urbanístico e de planejamento urbano. São elementos que, de alguma forma, incentivam ou limitam os assentamentos humanos e são de suma importância às empresas, já que eles ditam o percurso e o desenvolvimento que o país deseja obter.

Por último, foram avaliados os elementos socioculturais, tais como língua, costumes, práticas de negócios, nível e conteúdo educacional, os quais variam de país a país e influenciam no 
desempenho das empresas e suas estratégias de atuação (LORD; RANFT, 2000).

Por outro lado, a segunda parte da análise corresponde às características próprias do mercado residencial costarriquenho, a saber: tamanho, cultura instalada, taxa de crescimento e conformação.

Além disso, foram considerados elementos mais relativos a uma ordem estratégica, tais como demanda potencial, carência residencial, estoque residencial, nível de oferta máxima e ação da concorrência, que são fatores necessários para distinguir a atratividade nos diferentes segmentos de atuação, segundo aponta Alencar (1993).

Também foi analisado o sistema de financiamento e as características das linhas de crédito para empresas e pessoas, pois as atividades de real estate demandam importantes quantidades de recursos, de modo que a dependência pela disponibilidade de linhas de crédito integra as atividades desse setor como elemento indissociável para a implantação de empreendimentos residenciais.

Os resultados desta análise são apresentados na seção "Elementos de análise Swot".

\section{Empresas entrevistadas}

Foram aplicadas entrevistas a várias empresas brasileiras do setor, usando como base as informações da análise Swot, com o objetivo de ilustrar a tomada de decisões por parte desse grupo de empresas ante a proposta da internacionalização no mercado costarriquenho.

$\mathrm{Na}$ primeira parte, de maneira sintetizada, foi fornecido um relatório com dados do mercado costarriquenho, divididos em oportunidades e ameaças. A segunda parte consta de um formulário, que se inicia com a tomada de decisões sobre o interesse da empresa entrevistada em internacionalizar suas atividades para o mercado da Costa Rica; depois dessa etapa, mede-se a importância de cada oportunidade e a ameaça do mercado nessa decisão, para que se finalize com a nota de atratividade dada pelas empresas para o mercado.

Na última sessão do questionário são apresentadas forças e fraquezas no ambiente interno das empresas de real estate residencial para o processo de internacionalização. Nesse ponto, as empresas identificarão quais desses atributos e condições estão presentes nelas, podendo incrementar na parte das observações alguma outra força ou fraqueza não considerada no questionário.
O questionário foi respondido sempre com um dos autores presente, o qual conhece o mercado e poderia esclarecer qualquer dúvida do entrevistado.

\section{Escopo e limitações da entrevista}

O escopo da entrevista foi o aprofundamento na temática de estratégia empresarial para ilustrar a tomada de decisões de várias empresas ante a proposta da internacionalização no mercado residencial da Costa Rica.

$\mathrm{Na}$ aplicação do questionário foi encontrado como limitação o tipo de profissional capaz de respondêlo. Os entrevistados deveriam, por meio da ótica da empresa, avaliar as informações apresentadas acerca do mercado costarriquenho e respondê-lo segundo a possível reação da empresa. Também, deveriam conhecer as características e competências referentes ao desempenho da empresa com relação a suas atividades no mercado local nos últimos anos.

Por isso foram entrevistados os profissionais que tomam parte nesse tipo de decisões nas empresas, tais como presidentes, sócios, diretores executivos, diretores financeiros e diretores de relações com investidores e instituições. Devido à dificuldade de poder marcar uma entrevista com esses profissionais, escolheu-se entrevistar unicamente um membro por empresa, mas aprofundar questões estratégicas da empresa no momento da entrevista.

As empresas entrevistadas também tiveram uma prévia escolha, pois elas devem ter a estrutura e os recursos suficientes para considerar a realização desse tipo de empreendedorismo.

A partir dessas premissas foi feito um chamado a várias empresas do setor que colaboraram, em outros momentos, com o núcleo de pesquisa do qual os autores fazem parte, sendo aceito o convite por 11 empresas do setor residencial. Entre elas estão construtoras, incorporadoras, gestora de fundos, loteadoras e planejadoras de bairros, com operações nas regiões metropolitanas em vários estados do Brasil, principalmente naqueles com a maior movimentação econômica, abrangendo toda a gama de rendas, desde alto padrão até supereconômico.

As empresas entrevistadas e o profissional entrevistado se elencam (em ordem alfabética) a seguir: Brookfield Incorporações (Diretor Executivo), Camargo Corrêa Desenvolvimento Imobiliário (Diretor de Incorporação), Cipasa Urbanismo (CFO Diretor Financeiro e Administrativo), Cury Construtora e Incorporadora S.A. (Diretor de Relações Institucionais), Eztec Empreendimentos e Participações S.A. (Diretor

290 Navarro, F. A. R.; Alencar, C. 
Financeiro e de Relações com Investidores), Living (Diretor de Incorporação), Rocontec (Diretor Executivo e Sócio), RRG Construtora (Diretor) e VBI Real Estate (Sócio).

Duas das empresas entrevistadas pediram sigilo na participação na pesquisa, e por isso uma breve descrição delas e sua relevância no setor residencial são apresentadas:

(a) empresa A: com mais de 100 anos de história em São Paulo, reconhecida no mercado brasileiro pela atuação no planejamento de bairros, projetos e requalificação de áreas urbanizadas; com investimentos em vários países de América do Sul; e

(b) empresa B: fundada há mais de 10 anos, empresa de capital aberto de grande porte, com atuação concentrada em regiões metropolitanas dos estados do Rio de Janeiro, Minas Gerais, São Paulo e Rio Grande do Sul; opera no segmento residencial de média renda e de alto padrão, além do setor comercial.

\section{Elementos de análise Swot}

Apresenta-se nesta seção a avaliação interna e externa para o estudo da possível internacionalização de empresas brasileiras de real estate residencial no mercado da Costa Rica.

\section{Forças e fraquezas de empresas de real estate residencial}

A partir da análise do ambiente interno das empresas de real estate residencial em processo de internacionalização distinguiram-se 12 forças e 10 fraquezas.

Do total das forças as primeiras quatro correspondem àquelas características que ajudariam a internacionalizar o foco habitual de atuação das atividades da empresa; e as oito restantes correspondem às habilidades próprias do negócio de real estate, as quais seriam indispensáveis no novo mercado a explorar.

As principais forças (strengths) das empresas de real estate residencial seriam as seguintes.

S.1 Capacidade de criar novas competências dependendo das condições do mercado e da estratégia implementada.

S.2 A empresa desenvolve competências que são refletidas em seus produtos no mercado local, mostrando uma atuação diferenciada da concorrência.

S.3 A empresa desenvolve boas relações com parceiros externos.
S.4 A empresa possui parceiros econômicos interessados em diversificar seus investimentos em mercados internacionais.

S.5 Há entendimento dos ciclos e processos do mercado local, refletindo um adequado planejamento, desenho e marketing do produto, o que atende às expectativas dos clientes.

S.6 A empresa responde adequadamente às ameaças externas com sua estrutura organizacional e suas estratégias empresariais adaptáveis.

S.7 A empresa pode reconhecer o risco de seus investimentos antes e durante cada ciclo de investimento/retorno.

S.8 A empresa possui boa gestão dos recursos financeiros na área contável, de finanças corporativas e tributos.

S.9 A empresa possui competências nas áreas de project e construction management.

S.10 Recursos humanos, valores e filosofia empreendedora são capazes de enfrentar novos desafios, como a internacionalização da companhia.

S.11 Plataforma tecnológica é capaz de aproveitar as inovações dessa área.

S.12 Apresenta habilidades para prestação de serviços em áreas internacionais: gerência com domínio de outras línguas e conhecimento de finanças e economia internacional.

Entre as fraquezas foi feita a mesma divisão, sendo as 8 primeiras elementos que dificultariam a migração das atividades da empresa, e as 2 restantes, fatores próprios desse tipo de empresa que influenciariam o desempenho dela no estrangeiro.

As principais fraquezas (weaknesses) das empresas de real estate residencial seriam as seguintes.

W.1 A cultura empresarial da companhia possui muitos traços próprios da cultura "regional", que interferem no desenvolvimento das atividades de negócios com pessoas de outros países e culturas.

W.2 A empresa nunca interagiu com empresas estrangeiras no desenvolvimento de seus negócios.

W.3 A empresa apresenta uma cultura organizacional fechada, sem desejos de mudanças ou exploração de novos mercados. 
W.4 A empresa conta com estrutura administrativa rígida, desenhada unicamente para seu nicho de atuação.

W.5 A empresa conta com sistemas de controle familiar, é mais informal e baseada nas relações pessoais.

W.6 A empresa conta com sistemas de controle burocráticos, baseados em regras e normas rígidas.

W.7 A empresa não possui procedimentos formalizados e padronizados que podem ser replicados no estrangeiro por subsidiárias.

W.8 Recurso econômico limitado ou insuficiente para internacionalizar a empresa.

W.9 A empresa não consegue desenvolver novas competências, a não ser a altos preços, especialmente nos modelos de parceiras e outras alianças estratégicas.

W.10 A empresa carece de algumas competências básicas específicas das empresas de real estate residencial.

\section{Oportunidades e ameaças do mercado residencial da Costa Rica}

Distinguiu-se da análise ambiental um total de 24 oportunidades e de 20 ameaças. As primeiras 11 oportunidades e as 10 ameaças são derivadas das conjunturas econômicas, político-legais e socioculturais da Costa Rica, e o restante é derivado das características próprias do mercado residencial.

As oportunidades (opportunities) do mercado residencial costarriquenho seriam os seguintes.

O.1 Economia com inflação estável nos últimos cinco anos, com o Índice de Preços ao Consumidor (IPC) dentro das metas de inflação da atual política monetária: entre $4 \%$ e $6 \%$.

O.2 Importante e crescente Investimento Estrangeiro Direto (IED), nos últimos anos, na economia local. Em 2013, esse investimento foi de 2.714,2 milhões de dólares. As atividades imobiliárias em 2012 representaram 19\%, e em 2013 ao redor de $43 \%$.

O.3 Alta estabilidade política e transparência institucional no país.

O.4 Criação de políticas que promovam assentamentos humanos e ordenamento territorial, com simplificação de alvarás de construção, atualizando a legislação e incentivando as parcerias público-privadas (PPP) e operações urbanas.

O.5 Criação de políticas que incentivam o uso do solo nos principais centros urbanos, priorizando projetos residenciais de alta densidade que interajam com o entorno da cidade e o meio ambiente.

O.6 Criação de políticas que incentivem os investimentos para a renovação urbana do centro da capital (região de maior população), facilitando os créditos para as empresas e agilizando os alvarás de construção.

O.7 Criação de políticas que influam diretamente na gestão dos projetos residenciais com exoneração das taxas de construção nas prefeituras e aumentos dos coeficientes de aproveitamento do solo em projetos sustentáveis com o meio ambiente.

O.8 Criação de políticas que promovam a competitividade do país no que concerne a regulamentações, alvarás de construção, infraestrutura, financiamento, investimento local, eficiência governamental, investimento estrangeiro direto, desenvolvimento do capital humano e inovação.

O.9 Criação de políticas para agilizar os alvarás de construção e formalidades nas instituições públicas e incrementar a qualidade do serviço e da informação pelas vias virtuais.

O.10 País com nível educacional alto, recursos humanos especializados e centros de pesquisa e desenvolvimento.

0.11 País com localização estratégica para entrar no mercado norte-americano e outros blocos econômicos importantes.

O.12 A Costa Rica concentra a maior parte da população e das atividades econômicas no centro do país, o que favorece a centralização das atividades das empresas residenciais em determinada área.

O.13 Mais de dois quintos da população estão dentro dos lares com poder aquisitivo importante.

O.14 A carência residencial do país, segundo os índices para sua definição, se encontra na faixa de 184 mil a 670 mil unidades. Somente as famílias que alugam imóveis somadas às famílias que moram em imóveis em mau estado totalizam 383 mil unidades habitacionais. 
O.15 O estoque residencial do país é equivalente a $16 \%$ do montante das famílias que alugam e têm imóveis em mau estado.

O.16 Nos últimos anos foi registrado um crescimento anual de $2,64 \%$ na quantidade de famílias costarriquenhas, formadas, em sua maioria, por 3 ou 4 membros.

0.17 A Grande Área Metropolitana (GAM) precisará em 2030 de 250 mil novas moradias para seus 825 mil novos habitantes, segundo estimativas do Ministério de Moradia e Assentamentos Humanos.

O.18 Na Costa Rica o Sistema Financeiro Nacional é um sistema formal, estruturado e regulado.

O.19 Diversas alternativas para que as empresas de real estate financiem seus empreendimentos: empréstimos à empresa e estruturação de financiamentos.

0.20 O sistema bancário tem diversas alternativas para o financiamento de moradia própria.

0.21 As taxas de juros para moradia, momentaneamente, apresentam valores baixos, segundo registros históricos.

O.22 Estão em atuação várias políticas que tentam incentivar o acesso à moradia pela classe média, com auxílio, especialmente na entrada da compra do imóvel, a partir de algum tipo de subsídio.

O.23 Mudanças nas tendências de moradia, com aumento progressivo, nos últimos anos, dos metros quadrados tramitados para apartamentos e condomínios.

O.24 Níveis médios de renda são desconsiderados pela concorrência local de grandes projetos residenciais.

As ameaças (threats) do mercado residencial costarriquenho seriam:

T.1 O país tem uma economia suscetível aos acontecimentos globais e depende dos mercados norte-americano e europeu.

T.2 O país tem uma economia em recuperação após a Crise Mundial de 2008, mas ainda não tem estabilidade consolidada diante das incertezas e ações dos mercados internacionais.

T.3 Um país com crescimento da dívida do setor público nos últimos anos, o que poderia afetar a sustentabilidade e solvência econômica nacional, influenciando no aumento das taxas de juros e inflação.

T.4 Um país sem melhoria nos indicadores sociais, com indicadores de pobreza, desemprego e desigualdade constantes nos últimos anos.

T.5 Embora haja a política de "bandas cambiárias" da Costa Rica, podem ocorrer mudanças abruptas do câmbio da moeda local ante o dólar, por condições exógenas, em curto tempo.

T.6 Legislação urbanística com deficiências, desatualizações e pouca abrangência no território local.

T.7 O país apresenta gargalos em competitividade ligados à deterioração e ao atraso de infraestrutura rodoviária, portuária e aeroportuária.

T.8 País com entraves legais e burocráticos nos processos produtivos.

T.9 Baixa proteção ao investidor minoritário em sociedades anônimas.

T.10 Alto risco ocasionado por fenômenos naturais: $36,8 \%$ da superfície continental do país é exposta a três ou mais fenômenos naturais.

T.11 Tamanho do mercado costarriquenho, atualmente com 4,7 milhões de habitantes. Espera-se um crescimento de $39 \%$ até o final deste século, um total de 6,50 milhões de habitantes.

T.12 A cultura instalada no mercado residencial costarriquenho é a de moradia em casas de um ou dois andares. Há pouca representatividade de prédios como moradia predileta.

T.13 O sistema financeiro da Costa Rica não tem nenhuma diretriz da quantidade de recursos que os bancos devem destinar a esse fim; cada banco estabelece suas políticas creditícias e os fundos destinados para cada produto ou linha de financiamento.

T.14 As instituições financeiras podem investir, em uma empresa ou grupo de interesse econômico, o montante máximo de $20 \%$ de seu patrimônio, dependendo das políticas internas bancárias.

T.15 A quantidade de requisitos solicitados pelos bancos para financiamentos, somados à complexidade e ao tempo gasto para se obterem os alvarás de construção, ocasiona o redirecionamento bancário dos recursos a outros projetos. 
T.16 A dinâmica dos sistemas de financiamento pode desmotivar a aquisição de empréstimo para moradia a clientes de projetos residenciais pelo número de requisitos, tempo de aprovação, custos de formalização e estruturação das taxas de juros.

T.17 Pouca poupança acumulada ou carência de uma cultura de poupança pelas famílias costa-riquenhas.

T.18 Os bancos passaram a ter comportamento mais cauteloso depois da crise de 2008, com diminuição de recursos disponibilizados à moradia e com acompanhamento dos resultados da economia local.

T.19 Setor empresarial local com autonomia suficiente para desenvolver projetos residenciais.

T.20 Concorrência local focada em estratos de renda média-alta e alta, desenvolvendo alto conhecimento sobre esses segmentos.

\section{Principais resultados das entrevistas}

O resumo dos principais resultados é mostrado nos seguintes pontos, incrementados com comentários dos entrevistados no momento da entrevista.

\section{Avaliação dos elementos externos: oportunidades e ameaças do mercado}

A escala designada no questionário para cada elemento estratégico foi a seguinte: nada importante (1), pouco importante (2), medianamente importante (3), importante (4) e imprescindível (5).

No momento da tomada de decisões sobre estudar uma internacionalização na Costa Rica, as oportunidades e ameaças das conjunturas econômicas, político-legais e socioculturais receberam pontuações em torno de 3,5, enquanto os fatores próprios do mercado receberam maior atenção pelas empresas, com uma pontuação em torno de 4,0. Em ambos os casos as ameaças receberam maior pontuação pelos entrevistados (ver Tabela 1).

Os principais resultados individuais da avaliação de cada uma das oportunidades e ameaças nas entrevistas são apresentados na Tabela 2.

Tabela 1 - Importância das oportunidades e ameaças na tomada de decisões

\begin{tabular}{|c|c|c|}
\hline Elementos externos & Oportunidades & Ameaças \\
\hline Econômico, político-legal e sociocultural & 3,36 & 3,59 \\
\hline Próprios do mercado & 3,86 & 4,05 \\
\hline Total & 3,76 & 3,95 \\
\hline
\end{tabular}

Tabela 2 - Valoração das oportunidades e ameaças do mercado costa-riquenho

\begin{tabular}{lcc}
\hline \multicolumn{1}{c}{ Elementos avaliados* } & \multicolumn{1}{c}{$\begin{array}{c}\text { Pontuação } \\
\text { média }\end{array}$} & \begin{tabular}{c} 
Oportunidade (O) \\
\multicolumn{1}{c}{ Desvio } \\
padrão
\end{tabular} \\
\hline $\begin{array}{l}\text { Diversas alternativas de financiamento para empresas e público } \\
\text { (O.19 e O.20) }\end{array}$ & 4,5 & 0,5 \\
\hline \begin{tabular}{l} 
Ameaça (T) \\
\multicolumn{1}{c}{ Amas taxas de juros do mercado costa-riquenho para créditos (O.21) }
\end{tabular} & 4,2 & 0,6 \\
\hline $\begin{array}{l}\text { O tamanho do mercado residencial (T.11) } \\
\begin{array}{l}\text { Os entraves do sistema financeiro para créditos a empresas de real } \\
\text { estate residencial (T.15) }\end{array}\end{array}$ & 4,5 & 0,8 \\
$\begin{array}{l}\text { Os entraves do sistema financeiro para créditos de moradia própria } \\
\text { (T.16) }\end{array}$ & 4,5 & 0,7 \\
$\begin{array}{l}\text { Pouca ou carência de poupança acumulada pelas famílias costa- } \\
\text { riquenhas (T.17) }\end{array}$ & 4,6 & 0,7 \\
\hline
\end{tabular}

Nota: *a informação entre parênteses se refere a sua respectiva classificação. 
Depois dessa avaliação dos fatores externos perguntou-se sobre o interesse da empresa em internacionalizar suas atividades para o mercado da Costa Rica. Segundo as informações apresentadas a maioria das respostas foram negativas (Figura 2), classificando o mercado em questão como "pouco atrativo", em sua maioria, pois essas empresas não encontram nenhuma oportunidade ou vantagem de alto valor que torne o mercado costa-riquenho atrativo (Figura 3).

Cabe realçar que $64 \%$ dos entrevistados responderam que a informação é suficiente para um "não" ou "ainda não", mas que, caso algum desses dados tivesse chamado a atenção, precisariam de um relatório mais customizado, com informação mais detalhada, segundo o interesse da empresa.

Para o percentual restante dos entrevistados a qualidade da informação não influenciou na tomada de decisões, pois não estão interessados na expansão geográfica da empresa. Ainda assim, os entrevistados analisaram do ponto de vista estratégico os elementos do mercado costariquenho e seu ambiente interno para uma hipotética internacionalização.

A única empresa que mostrou interesse no mercado costa-riquenho é uma empresa com perfil internacional, pelo que não haveria problemas em analisar esse novo mercado entre seus possíveis mercados de atuação.

\section{Avaliação dos elementos internos: forças e fraquezas das empresas}

Quando se perguntou sobre as forças que ajudariam as empresas de real estate no processo de internacionalização, das 12 forças elencadas as 5 mais comuns para as empresas foram:

(a) "a empresa possui competências nas áreas de project e construction management" (S.9), em 9 das 11 empresas;

(b) "a empresa pode reconhecer o risco de seus investimentos, antes e durante cada ciclo de investimento/retorno" (S.7), em 8 das 11 empresas;

(c) “a empresa possui boa gestão dos recursos financeiros na área contável, de finanças corporativas e de tributos" (S.8), em 8 das 11 empresas;

(d) "entendimento dos ciclos e processos do mercado local, refletindo um adequado planejamento, desenho e marketing do produto, cumprindo as expectativas dos clientes" (S.5), em 7 das 11 empresas; e

(e) "capacidade de criar novas competências, dependendo das condições do mercado e da estratégia implementada" (S.1), em 7 das 11 empresas.

Figura 2 - Interesse em estudar o mercado da Costa Rica

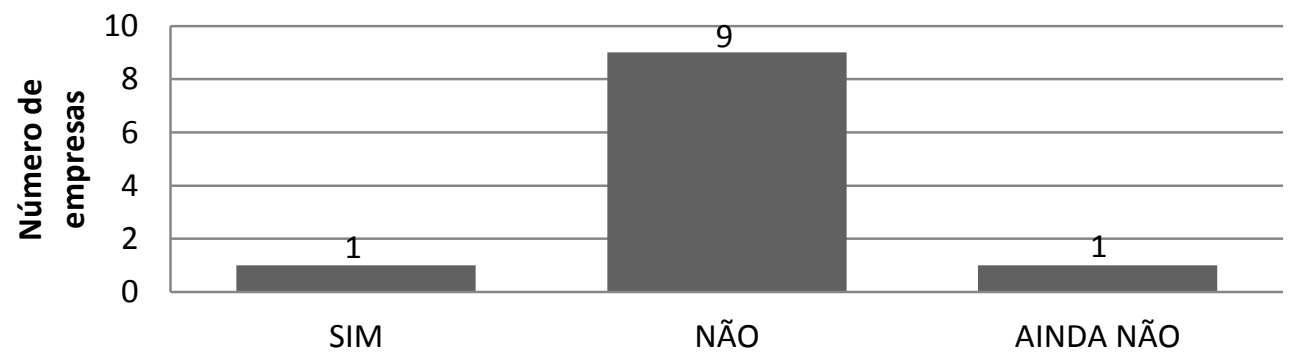

Figura 3 - Atratividade do mercado costarriquenho

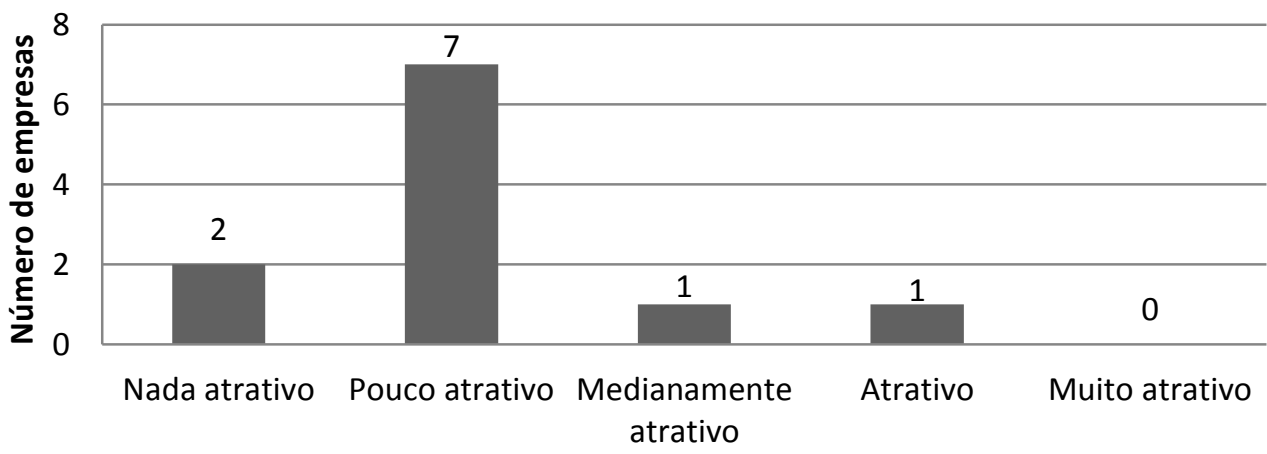


Entre as 10 fraquezas elencadas, a grande maioria concordou (7 das 11 empresas) que um obstáculo para a internacionalização, tanto na Costa Rica como em qualquer país, seria que "a cultura empresarial da companhia possui muitos traços próprios da cultura regional, que interferem no desenvolvimento das atividades de negócios com pessoas de outros países e culturas" (W.1).

Além disso, concordaram que outros obstáculos seriam "o recurso econômico limitado ou insuficiente para internacionalizar a empresa" (W.8) (4 das 11 empresas) e "a estrutura administrativa rígida da empresa, desenhada unicamente para seu nicho de atuação" (W.4) (3 das 11 empresas); este último elemento se relaciona, em parte, à cultura empresarial.

$\mathrm{O}$ restante das respostas recebeu pontuações menores.

\section{Outras observações}

Entre as observações feitas pelas empresas, destaca-se a carência de um driver sólido que as conduzam a esse mercado. Tamanho de mercado, culturas, línguas, distância geográfica, carência de conhecimento local ou de parceiros locais, produtividade e diferenças no custo do dinheiro seriam obstáculos ao ganho atrativo de lucro, comparado ao risco incidido.

Além disso, várias empresas não se interessam em deslocamentos internacionais porque as condições econômicas e as dimensões do mercado residencial brasileiros ainda propiciam oportunidades para que os objetivos empresariais, planejados em médio prazo, possam ser atingidos, com espaço suficiente para as empresas continuarem crescendo.

Por último, os mercados mais próximos geograficamente e com vantagens mais tangíveis, como as oferecidas nos países do Mercado Comum do Sul (Mercosul), seriam os primeiros alvos, em caso de internacionalização das atividades empresariais brasileiras.

Apesar disso, mercados internacionais distantes podem ser atraídos, enquanto sejam apurados menores riscos nesse tipo de negócio. Há como exemplos a garantia de quantidade considerável de unidades a se desenvolver e facilidades no fornecimento de materiais e mão de obra por parte de terceiros, como governo, organizações internacionais e investidores locais.

\section{Discussão de resultados}

A estruturação dos elementos internos e externos que deveriam ser analisados num processo de internacionalização, elencados na metodologia e apresentados na seção "Elementos de análise Swot" para este caso em particular, levou a maioria das empresas entrevistadas a uma negativa sobre a possível internacionalização de suas atividades no mercado residencial da Costa Rica.

$\mathrm{Na}$ avaliação externa de elementos gerais do país as empresas entrevistadas não encontraram no ambiente econômico, nas políticas, nas legislações e nos elementos culturais do país alguma oportunidade importante que possa tornar atrativo esse mercado, recebendo esses itens uma pontuação baixa $(3,36)$, de medianamente importante. Muitas das empresas entrevistadas concluem pela importância de drivers sólidos nas economias estrangeiras para atrair investimentos, como as oferecidas mais claramente nos países do Mercosul para este caso.

$\mathrm{Na}$ segunda parte da avaliação externa, que correspondeu às características próprias do mercado e aos elementos mais de ordem estratégica, os fatores obtiveram a atenção das empresas entrevistadas, com as maiores pontuações, as quais focaram sua atenção no tamanho do mercado costa-riquenho e nas condições do sistema financeiro do setor moradia, como possíveis ameaças para o desenvolvimento de negócios nos patamares de rentabilidade desejado. Zapletalova (2014) argumenta que tomar vantagens das oportunidades dos mercados internacionais requer preparação e conhecimento de suas particularidades e singularidades.

O desinteresse em mercados estrangeiros apresentado nas empresas entrevistadas e em muitas empresas brasileiras é justificado por DalSoto, Alves e Bulé (2014), devido ao potencial significativo em seus mercados domésticos, o que retarda ou descarta a internacionalização. No caso do mercado residencial brasileiro, este apresenta condições favoráveis, com um significativo crescimento em volume de obra devido à redução da taxa básica de juros e à maior disponibilidade de crédito para o financiamento da aquisição habitacional e construção de moradias (SOUZA, 2011).

Quanto à análise dos elementos do ambiente interno, divididos em intrínsecos a seu negócio e necessários para ampliar o foco habitual de atuação, o comum das forças distinguidas nas entrevistas corresponde às habilidades básicas e de desempenho para empresas de real estate, e nenhuma referente à internacionalização, isso possivelmente motivado pelas condições favoráveis de seus mercados locais, fortalecendo o conceito de consolidar-se em seus mercados domésticos como estratégia de crescimento. 
Por outro lado, a maior fraqueza ou obstáculo desses dois ambientes internos seria a estruturação de cultura empresarial e a carência de conhecimento local do novo mercado. Este último elemento seria um dos principais motivos que aumentam a chance de demora nas obras, além de sobrecustos e de operações instáveis das empresas que levam suas operações a níveis internacionais (LORD; RANFT, 2000). Assim também Javernick-Will (2009) mostra em seu trabalho que o problema do conhecimento local é amplo, particularmente para empresas do setor de real estate, as quais precisam das informações mercadológicas, legais e técnicas nos processos de tomada de decisões.

\section{Conclusões}

Conclui-se que empresas de real estate residencial poderiam utilizar uma metodologia de análise de fatores externos e internos similar à praticada nesta pesquisa, na qual se distingam as forças e fraquezas específicas da empresa nessa estratégia, e as oportunidades e ameaças do novo mercado, para a tomada de decisões sobre sua estratégia de expansão geográfica.

A avaliação do ambiente externo que considera as principais conjunturas econômicas, político-legais e socioculturais permite dar uma visão geral das condições do país em que se planeja investir. Com a segunda parte da análise, que foca sua atenção nos elementos próprios do mercado, as empresas reconhecem os elementos que poderiam ser favoráveis ou prejudiciais, segundo as características da empresa, suas habilidades e competências.

A avaliação do ambiente interno pode distinguir, além da competitividade da empresa em seu mercado local, se esta pode expandir suas atividades a novas culturas, com base em suas fraquezas e forças.

Para o caso particular deste trabalho, os resultados da pesquisa mostram que as empresas entrevistadas, com a informação fornecida, são capazes de tomar decisões sobre a atratividade dessa estratégia, respondendo, em sua maioria, negativamente a esta, pois elementos como a dimensão do mercado e as características do financiamento disponível não satisfazem suas expectativas. Além disso, as oportunidades apresentadas não são compensadas pelos riscos percebidos, pois carecem de algum conhecimento sobre esse novo mercado e/ou possuem uma cultura empresarial muito consolidada a seus mercados domésticos.

\section{Referências}

ALENCAR, C. T. de. A Tomada de Decisões Estratégicas no Segmento de Empreendimentos Residenciais: uma sistêmica de análise. 1993. 328 f. Dissertação (Mestrado em Engenharia Civil) Escola Politécnica, Universidade de São Paulo, São Paulo, 1993.

ALON, I.; BIAN, K. Real Estate Franchising: the case of Coldwell Banker expansion into China.

Business Horizons, v. 48, n. 3, p. 223-231, maio 2005.

ANSOFF, I. Estratégia Empresarial. São Paulo: McGraw-Hill do Brasil, 1977.

BARDHAN, A.; KROLL, C. A. Globalization and the Real Estate Industry: issues, implications, opportunities. In: SLOAN INDUSTRY STUDIES ANNUAL CONFERENCE, 2007, Cambridge: Haas School of Business, UC Berkeley. 2007.

DAL-SOTO, F.; ALVES, J. N.; BULÉ, A. E. Análise do Processo de Internacionalização do Modelo de Uppsala: caminhos para as empresas Brasileiras. Estudo \& Debate em Gestão \& Planejamento, v. 1, n. 21, p. 179-199, 2014.

DYSON, R. G. Strategic Development and Swot Analysis at the University of Warwick. European Journal of Operational Research, v. 152, n. 3, p. 631-640, 2004.

GIBLER, K. M.; BLACK R. T.; MOON K. P. Time, Place, Space, Technology and Corporate Teal Estate Strategy. Journal of Real Estate Research, v. 24, n. 3, p. 235-262, 2002.

JAVERNICK-WILL, A. N. Organizational Learning During Internationalization: acquiring local institutional knowledge. Construction Management and Economics, v. 27, n. 8, p. 783797, ago. 2009.

JUNG, W. et al. Empirical Assessment of Internationalization Strategies For Small and Medium Construction Companies. Journal of Construction Engineering and Management, v. 136, n. 12, p. 1306-1316, 2010.

KOTLER, P. Marketing Management. 10. ed. New Jersey: Prentice Hall, 2000.

KOTLER, P.; KELLER K. Administração de Marketing. 12. ed. São Paulo: Pearson Prentince Hall, 2006. 
LINJIE, C. Research on the Core Competencies Identification and Evaluation of Real Estate Enterprise. In: INTERNATIONAL CONFERENCE ON E-BUSINESS AND EGOVERNMENT, Shanghai, 2011. Proceedings... Shanghai, 2011.

LORD, M. D.; RANFT, A. L. Organizational Learning About New International Markets: exploring the internal transfer of local market knowledge. Journal of International Business Studies, v. 31, n. 4, p. 573-589, dez. 2000.

MANNING, C.; EPLEY D. Do Real Estate Faculty Teach the Skills and Competencies Needed by Corporate Real estate Executives? 2006. Disponível em:

$<$ http://www.researchgate.net/publication/2283705 56_Do_Real_Estate_Faculty_Teach_the_Skills_an d_Competencies_Needed_by_Corporate_Real_Est ate_Executives>. Acesso em: 11 mar. 2013.

MINISTÉRIO DE MORADIA E ASSENTAMENTOS HUMANOS. Propuesta de Plan de Ordenamiento Territorial de la Gran Área Metropolitana 2011-2030. Ministerio de Vivienda y Asentamientos Humanos, Costa Rica, 146 f. 2012.

NUMMELA, N.; SAARENKETO, S.; PUUMALAINEN, K. A Global Mindset: a prerequisite for successful internationalization?

Canadian Journal of Administrative Sciences / Revue Canadienne des Sciences de l'Administration, v. 21, n. 1, p. 51-64, mar. 2004.

OSLAND, G. E.; TAYLOR, C. R.; ZOU, S. Selecting International Modes of Entry and Expansion. Marketing Intelligence \& Planning, v. 19, n. 3, p. 153-161, jun. 2001.

PORTER, M. E. The Competitive Advantage of Nations. Harvard Business Review. 1990. Disponível em: <https://hbr.org/1990/03/thecompetitive-advantage-of-nations $>$. Acesso em: 7 dez. 2014.

PRAHALAD, C. K.; HAMEL, G. Estratégia Corporativa e Escopo Empresarial: 3. competência essencial da corporação. Rio de Janeiro: Campus, 1998.
PRANGE, C.; VERDIER, S. Dynamic Capabilities, Internationalization Processes and Performance. Journal of World Business, v. 46, n. 1, Africa Special Issue Section, p. 126-133, jan. 2011.

ROCHA LIMA, J. da J.; ALENCAR, C. T. Foreign Investment and the Brazilian Real Estate Market. International Journal of Strategic Property Management, v. 12, n. 2, p. 109-123, abr. 2008 .

SCHERER, F. L.; GOMES, C. M.; KRUGLIANSKAS, I. The Internationalization Process of Brazilian Companies: a study of multiple cases in the heavy construction industry. BAR - Brazilian Administration Review, v. 6, n. 4, p. 280-298, dez. 2009.

SOUZA, F. F. de A. Análise das Influências das Estratégias de Diversificação e dos Modelos de Negócios no Desempenho das Empresas de Real Estate no Período 2005 a 2010. São Paulo, 2011. 187 f. Dissertação (Mestrado em Engenharia de Construção Civil e Urbana) - Escola Politécnica, Universidade de São Paulo, São Paulo, 2011.

VARGAS, N. Organizações em Ambientes Internacionais Turbulentos: estudo de uma construtora multinacional brasileira. São Paulo, 2008. 161 f. Tese (Doutorado em Engenharia de Produção) - Escola Politécnica, Universidade de São Paulo, São Paulo, 2008.

ZAPLETALOVA, S. The Internationalization Process of Czech Companies. International Business Management, v. 8, n. 6, p. 361-368, 2014.

\section{Agradecimento}

Ao Ministério de Ciência, Tecnologia e Telecomunicações (Micitt) e ao Conselho Nacional para Pesquisas Científicas e Tecnológicas (Conicit) da Costa Rica, e ao Programa de Pós-Graduação em Construção Civil (PCC) da USP, pelo apoio recebido para o desenvolvimento deste projeto. Agradecimento também aos profissionais e empresas que aceitaram colaborar com o questionário da pesquisa. 
Fabrício Alonso Richmond Navarro

Escola Politécnica | Universidade de São Paulo | Av. Prof. Luciano Gualberto, 380, Butantã | São Paulo - SP - Brasil | CEP 05508-010 | Tel.: (11) 3091-9656 | E-mail: fabriciorichmond@hotmail.com

\section{Cláudio Alencar}

Escola Politécnica | Universidade de São Paulo | E-mail: claudio.alencar@poli.usp.br

\section{Revista Ambiente Construído}

Associação Nacional de Tecnologia do Ambiente Construído

Av. Osvaldo Aranha, $99-3^{\circ}$ andar, Centro

Porto Alegre - RS - Brasil

CEP 90035-190

Telefone: +55 (51) 3308-4084

Fax: +55 (51) 3308-4054

www.seer.ufrgs.br/ambienteconstruido

E-mail: ambienteconstruido@ufrgs.br 